\title{
FITOTECNIA
}

\section{CULTIVO E CARACTERÍSTICAS NUTRICIONAIS DE PLEUROTUS EM SUBSTRATO PASTEURIZADO $\left({ }^{1}\right)$}

\author{
EDUARDO BERNARDI $\left({ }^{2 *}\right)$; LORENA PASTORINI DONINI $\left({ }^{3}\right)$; ELISANDRA MINOTTO $\left({ }^{3}\right)$; \\ JOSÉ SOARES DO NASCIMENTO $\left({ }^{3}\right)$
}

\begin{abstract}
RESUMO
O objetivo deste trabalho foi avaliar a produtividade, eficiência biológica, massa fresca, composição centesimal dos cogumelos Pleurotus ostreatus (BF24) e Pleurotus sajor-caju (PSC96/03 e PSC01/06) produzidos no substrato capim-elefante (Pennisetum purpureum) pasteurizado e a relação Carbono/Nitrogênio inicial e final do substrato. O substrato seco e particulado a $2 \mathrm{~cm}$ foi umedecido por 24 horas e pasteurizado a $100{ }^{\circ} \mathrm{C}$ durante 30 minutos. Adicionaram-se 3\% de inóculo de cada linhagem, sendo acondicionado em embalagens de polipropileno com $1 \mathrm{~kg}$ cada uma. Os substratos foram incubados a $26{ }^{\circ} \mathrm{C}$ e na fase de frutificação a $23 \pm 3{ }^{\circ} \mathrm{C}$ e umidade relativa de $75 \%$ a $90 \%$. Na linhagem BF24 observou-se maior massa fresca $(281,19 \mathrm{~g})$, eficiência biológica $(112,46 \%)$ e produtividade $(28,11 \%)$. O substrato com relação Carbono:Nitrogênio inicial de 162:1 foi o de menor relação (68:1) após o cultivo do P. sajor-caju (PSC01/ 06). A linhagem PSC 96/03 proporcionou maior teor de proteína em relação às demais, tendo a BF24 maior teor de lipídios. Quanto ao teor de carboidratos e cinzas, nas diferentes espécies e linhagens não houve diferenças significativas; já para a quantidade de fibras, as linhagens BF24 e PSC01/06 foram similares, porém superiores a PSC96/03. As duas espécies de Pleurotus podem ser cultivadas em capimelefante pasteurizado, suprimindo o processo de compostagem.
\end{abstract}

Palavras-chave: Pleurotus ostreatus, Pleurotus sajor-caju, Pennisetum purpureum, eficiência biológica, produtividade.

${ }^{1}$ ) Recebido para publicação em 27 de setembro de 2007 e aceito em 14 de maio de 2009.

$\left(^{2}\right)$ Doutorando Programa de Pós-Graduação em Sistemas de Produção Agrícola Familiar - Laboratório de Micologia, Departamento de Microbiologia e Parasitologia, Instituto de Biologia, Universidade Federal de Pelotas, Campus Universitário s/n, Caixa Postal 354,96010-900 Pelotas (RS), Brasil. E-mail: bernardieduardo@yahoo.com.br (*) Autor correspondente.

( $\left.{ }^{3}\right)$ Departamento de Microbiologia e Parasitologia, Universidade Federal de Pelotas, Campus Universitário s/n, Caixa Postal 354, 96010-900 Pelotas (RS), Brasil. E-mail: lorenadonini@yahoo.com.br; elisminotto@yahoo.com.br; jsnufpel@hotmail.com 


\title{
ABSTRACT \\ CULTIVATION AND NUTRITIONAL CHARACTERISTICS OF PLEUROTUS GROWN IN PASTEURIZED SUBSTRATE
}

\begin{abstract}
The objective of this work was to evaluate the productivity, biological efficiency, fresh matter, and centesimal composition of mushroom Pleurotus ostreatus (BF24) and Pleurotus sajor-caju (PSC96/03 and PSC01/ 06) grown in pasteurized elephant grass substrate (Pennisetum purpureum). It was also assessed the initial and final Carbon/Nitrogen ratio. The dried 2-cm-particulate substrate was moist for 24 hours and pasteurized at $100^{\circ} \mathrm{C}$ during 30 minutes. Then, it was added $3 \%$ of inoculum of each strain. The substrate was placed into $1-\mathrm{kg}$ polypropylene bags. The bags were incubated at $26^{\circ} \mathrm{C}$ and relative humidity of 75 to $90 \%$. In the fructification phase they were incubated at $23 \pm 3^{\circ} \mathrm{C}$. The strain BF24 had the highest fresh matter $(281.19 \mathrm{~g})$, biological efficiency $(112.46 \%)$ and productivity $(28.11 \%)$. The substrate having initial Carbon/Nitrogen ratio of 162:1 showed the lowest final ratio (68:1), after P. sajor-caju (PSC01/06) cultivation. The strain PSC96/ 03 showed higher protein content than the others, and BF24 had the highest lipid content. There were no significant differences for carbohydrate and ash contents for the different species and strains. The strains BF24 and PSC01/06 had similar fiber amount, but higher than PSC96/03. The two species of Pleurotus can be cultivated in pasteurized elephant grass, supressing the composting process.
\end{abstract}

Key words: Pleurotus ostreatus, Pleurotus sajor-caju, Pennisetum purpureum, biological efficiency, productivity.

\section{INTRODUÇÃO}

Espécies de Pleurotus são conhecidas como cogumelos ostras, sendo cultivados em vários países, principalmente nos localizados no sudeste Asiático, Îndia, Europa e África. Naturalmente, este fungo é decompositor de madeiras e vários outros substratos (SiLva et al., 2002; MANDEel et al., 2005).

Os cogumelos devem ser apreciados não somente por sua textura e paladar, mas principalmente por suas propriedades químicas e nutricionais. Segundo Yilmaz et al. (2006), Pleurotus sp. possui propriedades como altos teores de proteínas, e algumas propriedades medicinais, como imunomodulatórias, anticancerígenas, antiinflamatória, antitrombótica, ações antivirais, e ainda, efeitos positivos sobre hipoglicemia e funções cardíacas. Muitos destes compostos já foram isolados, sendo os polissacarídeos os mais encontrados (HossAin et al., 2003; MANDEEL et al., 2005; Kim et al., 2006).

Segundo Mandeel et al. (2005), diferente de outros cogumelos, cogumelos ostras (Pleurotus spp.) são fáceis, rápidos e baratos para cultivar, pois requerem pouco tempo de preparação e baixa tecnologia de cultivo.

Vários resíduos ligno-celulósicos são descritos como substratos para o cultivo de Pleurotus spp., tais como palhas de cereais, bagaço de cana-de-açúcar, serragens, casca de frutas, folhas de bananeira, restos de papel, resíduos cítricos, polpa de café, entre outros. $\mathrm{Na}$ maioria dos cultivos, estes substratos são misturados a outras fontes nutricionais, com destaque para os farelos e uréia; desta forma, aumentam o tempo de preparo e os custos de produção (LI et al., 2001; EIRA, 2003; Moda et al. 2005).
Um dos fatores determinantes no cultivo de cogumelos é a seleção de substratos para produção, em que de acordo com TiSDALE et al. (2006), materiais adequados, tanto biológica como economicamente, são fundamentais para o sucesso do cultivo.

O objetivo deste trabalho foi avaliar a produtividade, eficiência biológica, massa fresca, composição centesimal dos cogumelos Pleurotus ostreatus (BF24) e Pleurotus sajor-caju (PSC96/03 e PSC01/06) produzidos no substrato capim-elefante (Pennisetum purpureum) pasteurizado e a relação Carbono/Nitrogênio inicial e final do substrato.

\section{MATERIAL E MÉTODOS}

O experimento foi desenvolvido em Pelotas (RS), e constou de um fatorial $A \times B$ ( $A=$ linhagens, $\mathrm{B}=$ fluxos de produção). $\mathrm{O}$ delineamento experimental, inteiramente casualizado, constou de seis repetições, sendo cada embalagem a unidade experimental. Foram utilizadas duas espécies de cogumelos, sendo uma linhagem de Pleurotus ostreatus (BF24) e duas de Pleurotus sajor-caju (PSC96/03 e PSC01/06). As linhagens BF24 e PSC96/03 originadas do Módulo de Cogumelos FCA/UNESP, Botucatu (SP), e a linhagem PSC01/ 06 oriunda da Universidade Federal de Lavras, Lavras (MG), sendo todas depositadas na micoteca do LEMICO/DEMP/IB/UFPel. Foram avaliados dois fluxos de produção, de 30 dias cada um.

As linhagens foram multiplicadas em meio de cultura à base de capim-elefante, dextrose e ágar (Donini et al., 2005) e incubadas a $26{ }^{\circ} \mathrm{C}$ por 5 dias, para obtenção de crescimento miceliano. 
Para o preparo do inóculo (spawn) foram utilizados grãos de sorgo (Sorghum bicolor L. Moench), previamente cozidos por 15 minutos, adicionados de $1 \%$ de gesso agrícola. Após a mistura, foram acondicionados em frascos de vidro de $8,6 \times 14 \mathrm{~cm}$, os quais foram fechados com papel alumínio e filme plástico e autoclavados a $121^{\circ} \mathrm{C}(1 \mathrm{~atm})$ por 45 minutos . Discos de $10 \mathrm{~mm}$ de diâmetro de cultura, previamente preparada conforme descrito anteriormente, foram transferidos assepticamente para os frascos com a mistura esterilizada e incubados a $28{ }^{\circ} \mathrm{C}$ até a colonização dos grãos pelo fungo (BERNARDI, 2007).

Como substrato foi utilizado o capim-elefante (Pennisetum purpureum Schum) o qual foi cortado ainda quando estava em estado vegetativo, fragmentado em tamanho de $2 \mathrm{~cm}$, e seco a temperatura ambiente.

Para a realização do ensaio, o capim-elefante foi previamente umedecido por 24 horas até umidade aproximada de $60 \%-70 \%$, sendo posteriormente acondicionado em sacos de polipropileno de alta densidade e submetidos a tratamento com vapor a 100 ${ }^{\circ} \mathrm{C}$ por 30 minutos.

Após o resfriamento do substrato, a aproximadamente $30{ }^{\circ} \mathrm{C}$, foi-lhe adicionado $3 \%$ de inóculo. Para isto, o substrato foi homogeneizado com o inóculo em uma bandeja de plástico e acondicionado em sacos plásticos, com orifícios de $5 \mathrm{~mm}$, contendo $1 \mathrm{~kg}$ de substrato úmido cada um, e armazenados em prateleiras à temperatura ambiente de $26 \pm 3{ }^{\circ} \mathrm{C}$ durante a fase de colonização, por 20 dias.

Após a completa colonização, os sacos foram transferidos para câmara de frutificação com temperaturas entre $25 \pm 3{ }^{\circ} \mathrm{C}$ e umidade relativa do ar de $75 \%$ a $90 \%$, com 24 horas de luminosidade. A colheita dos cogumelos iniciou-se aos 24 dias após a inoculação dos fungos no substrato, extendendo-se durante 80 dias de produção, compreendendo dois fluxos de 40 dias cada um. Cada fluxo foi caracterizado pela estagnação na frutificação e consequente inundação dos sacos em água, dando assim início a um novo fluxo de cultivo.

Os cogumelos foram coletados manualmente e as variáveis avaliadas foram massa fresca, produtividade em base úmida (KopYTOWSKI FILHO, 2002) e eficiência biológica (EIRA, 2003), calculados, respectivamente, da seguinte forma: Produtividade $(\%)=$ Massa úmida de cogumelo/Massa úmida de substrato x 100 e Eficiência Biológica (\%)= Massa úmida de cogumelo/Massa seca de substrato x 100 .

As análises de carbono e nitrogênio total do substrato, anterior e posteriormente à fase de produção, foram realizadas no Departamento de
Solos/FAEM/UFPel de acordo com os métodos Walkey-Black para carbono orgânico e Semi microKjeldahl para nitrogênio (Tedesco et al., 1995).

Os cogumelos foram coletados manualmente e separados de acordo com os tratamentos, desidratados, homogeneizados e caracterizados, em triplicata, com relação à sua composição centesimal de acordo com as Normas Analíticas do Instituto Adolfo Lutz (1985). A determinação de carboidratos foi obtida subtraindo-se de 100 a soma dos demais parâmetros.

Os resultados foram submetidos à análise da variação e teste de Duncan para comparação das médias, utilizando-se o programa estatístico SANEST (ZONTA e MACHADO, 1984).

\section{RESULTADOS E DISCUSSÃO}

Para a linhagem BF24 de P. ostreatus e as linhagens PSC96/03 e PSC01/06 de P. sajor-caju a formação de primórdios ocorreu aos 20, 30 e 33 dias, após o substrato ser submetido à inoculação a primeira colheita de todas as linhagens ocorreu quatro dias após a formação de primórdios.

Os valores totais obtidos para massa fresca, eficiência biológica e produtividade, independentemente dos fluxos de produção, foram significativamente superiores para a linhagem BF24 de P. ostreatus; nas linhagens PSC96/03 e PSC01/06 de P. sajor-caju não houve diferenças entre si, para as variáveis anteriormente citadas, conforme se observa na tabela 1. Durante o primeiro fluxo de produção, estas três linhagens não diferiram entre si para massa fresca, eficiência biológica e produtividade. Entretanto, no segundo fluxo de produção, na linhagem BF24 as médias foram superiores às das outras linhagens para as três variáveis analisadas, enquanto entre as duas linhagens de $P$. sajor-caju não houve diferenças significativas. Também foram verificados valores menores para as variáveis no segundo fluxo de produção, fato já demonstrado por ZHANG et al. (2002), em cultivo de P. sajor-caju sobre palhas de arroz e trigo. Deste modo, estas linhagens de Pleurotus sp. possuem aproximadamente $90 \%$ de produtividade no primeiro fluxo, que ocorreu entre 25 e 40 dias de cultivo.

Ragunathan e Swaminathan (2003) cultivando $P$. sajor-caju em vários resíduos agrícolas, obtiveram eficiência biológica máxima de $41,42 \%$, para linhagens deste cogumelo, quando cultivado em resíduos da cultura do algodão, valor inferior aos observados neste trabalho. 
Tabela 1. Massa fresca, eficiência biológica e produtividade de Pleurotus ostreatus (BF24) e Pleurotus sajor-caju (PSC96/ 03 e PSC01/06) cultivados em capim-elefante pasteurizado em dois fluxos de produção

\begin{tabular}{|c|c|c|c|c|}
\hline \multirow{2}{*}{ Variável } & \multirow{2}{*}{ Linhagem } & \multicolumn{2}{|c|}{ Fluxo } & \multirow{2}{*}{ Total } \\
\hline & & 1 & 2 & \\
\hline \multirow[t]{3}{*}{ Massa fresca $(\mathrm{g})$} & BF24 & $199,30 \mathrm{a} A$ & $81,72 \mathrm{a} B$ & $281,19 a$ \\
\hline & PSC96/03 & $198,84 a \mathrm{~A}$ & $24,30 \mathrm{~b} \mathrm{~B}$ & $223,15 b$ \\
\hline & PSC01/06 & 201,49 a A & $20,75 b$ B & $222,24 b$ \\
\hline \multirow[t]{3}{*}{ Produtividade (\%) } & BF24 & $19,96 a \mathrm{~A}$ & $8,18 \mathrm{a}$ B & $28,11 a$ \\
\hline & PSC96/03 & $19,88 \mathrm{a} A$ & $2,41 \mathrm{~b} \mathrm{~B}$ & $22,31 b$ \\
\hline & PSC01/06 & $20,15 a \mathrm{~A}$ & $2,08 \mathrm{~b} \mathrm{~B}$ & $22,23 b$ \\
\hline \multirow[t]{3}{*}{ Eficiência biológica (\%) } & BF24 & $79,71 \mathrm{a} A$ & $32,68 \mathrm{a} B$ & $112,46 a$ \\
\hline & PSC96/03 & $79,54 a \mathrm{~A}$ & $9,73 \mathrm{~b} \mathrm{~B}$ & $89,28 b$ \\
\hline & PSC01/06 & $80,61 \mathrm{a} A$ & $8,30 \mathrm{~b} B$ & $88,90 \mathrm{~b}$ \\
\hline
\end{tabular}

Médias seguidas de mesma letra minúscula, nas colunas, e maiúscula, nas linhas, não diferem entre si pelo teste de Duncan ( $\alpha=0,05)$.

Resultados de eficiência biológica para $P$. sajor-caju mais próximos aos obtidos neste trabalho foram os citados por KALMIS e SARGIN (2004), com valor de $70,20 \%$ para a variável quando esta espécie foi cultivada em palha de trigo. O cultivo de $P$. sajor-caju em bagaço de cana-de-açúcar pasteurizado foi avaliado por Moda et al. (2005); estes autores verificaram eficiência biológica de $13,86 \%$, valor muito inferior aos obtidos neste trabalho, comprovando, deste modo, a necessidade de seleção de substratos e linhagens para o cultivo desta espécie de cogumelos. Os mesmos autores citam a utilização de $5 \%$ de inóculo em relação à massa úmida do substrato, enquanto neste experimento foi usado $3 \%$, fato que aumenta o custo final de produção. Mesmo com menor percentual de inóculo a colonização foi rápida e não houve desenvolvimento de contaminantes.

Já YiLDIZ et al. (2002), cultivando P. ostreatus em diferentes substratos, obtiveram resultados de eficiência biológica superiores aos deste trabalho; esses autores observaram $121,2 \%$ de eficiência biológica quando utilizada a mistura (1:1) de resíduos de papel e palha de trigo, e $79,4 \%$ para a mesma variável, quando utilizada somente a palha de trigo. Relação similar também foi obtida por VelázQuezCedeño et al. (2002), utilizando polpa de café e a linhagem IE38 de $P$. ostreatus, chegando a $125 \%$ de eficiência biológica, valor $10 \%$ superior aos verificados neste trabalho. Logo, CURvetTo et al. (2002) cultivando cinco diferentes linhagens de P. ostreatus, em substrato à base de casca de semente de girassol, obtiveram eficiência biológica variando de $37,2 \%$ a $73,6 \%$, valores até $66,9 \%$ inferiores aos obtidos neste experimento.

O cultivo foi realizado com uma relação C/N inicial de 162:1 (Tabela 2) para as três linhagens de Pleurotus sp., considerada alta, comparando-se com as relações descritas por EIRA e MinHONI (1997) os quais citam relação C:N entre 80-100:1 para o cultivo deste gênero de cogumelos. Após o cultivo, verifica-se no substrato onde foi cultivada a linhagem PSC01/06 de $P$. sajor-caju a menor relação $\mathrm{C}: \mathrm{N}$, seguida por $P$. ostreatus (BF24) e P. sajor-caju (PSC96/03), variando entre 68:1 e 78:1. Neste caso, houve uma conversão em biomassa, em mais de $50 \%$ do carbono inicial do substrato, demonstrando o potencial lignocelulósico deste cogumelo.

Tabela 2. Relação C/N inicial e final do substrato (Pennisetum purpureum) utilizado no cultivo de Pleurotus ostreatus e Pleurotus sajor-caju

\begin{tabular}{lcc}
\hline Espécie de cogumelo & Relação C/N inicial & Relação C/N final \\
\hline Pleurotus ostreatus (BF24) & $162: 1 \mathrm{a} \mathrm{A}$ & $73: 1 \mathrm{~b}$ B \\
Pleurotus sajor-caju (PSC96/03) & $162: 1 \mathrm{a}$ A & $78: 1 \mathrm{a}$ B \\
Pleurotus sajor-caju (PSC01/06) & $162: 1 \mathrm{a} \mathrm{A}$ & $68: 1 \mathrm{c}$ B \\
\hline
\end{tabular}

Médias seguidas de mesma letra minúscula, nas colunas, e maiúscula, nas linhas, não diferem entre si pelo teste de Duncan ( $\alpha=0,05)$. 
Ao se analisar a produtividade e eficiência biológica (Tabela 1) dos cogumelos produzidos neste trabalho e a relação C:N inicial do substrato (Tabela 2), pode-se verificar que a utilização de capim-elefante para o cultivo destas três linhagens de cogumelos não requer a suplementação com outros materiais. Diferentemente de STURION (1994), que cita que na fase de desenvolvimento dos basidiomas a existência de uma relação $\mathrm{C} / \mathrm{N}$ baixa do substrato de cultivo é mais favorável. Já para ZANETTI e RANAL (1997), se por um lado o baixo teor de $\mathrm{N}$ diminui a produtividade, por outro lado, teores elevados desse nutriente também afetam negativamente a produção de basidiomas, onde existe uma concentração ideal de $\mathrm{N}$ para miceliação e produção, mas divergências no método e no cálculo dificultam a identificação desse valor.

Logo, de acordo com alguns autores existe a necessidade de suplementação dos substratos utilizados no cultivo de cogumelos, objetivando incrementar os valores de produtividade e eficiência biológica. Assim, Vogel e Salmones (2000) adicionaram farinha de soja na proporção de 5,5\% à massa seca do substrato composta por palha de trigo, e observaram eficiência biológica de $58,8 \%, 64,8 \%$ e $80,47 \%$, respectivamente, para as linhagens IE-227, 1314 e IE-226 de Pleurotus spp. A casca de semente de girassol suplementada com 0 a 750 ppm de $\mathrm{NH}_{4}{ }^{+}$ para a produção de $P$. ostreatus, segundo CuRvetTo et al. (2002), aumenta a produtividade desta espécie em até $50 \%$, através da adequação da relação $\mathrm{C} / \mathrm{N}$ do substrato, hipótese discutida por ROYse (2002) para a produção de $P$. cornucopiae.

WANG et al. (2001), ao pesquisarem o cultivo de $P$. ostreatus verificaram que a suplementação do substrato, à base de palha de cevada, com farelo de trigo até $45 \%$ proporcionou aumento na eficiência biológica do cogumelo, fato corroborado por DiAs et al. (2003) em substrato à base de palha de milho pura e com suplementação de $10 \%$ de farelo de trigo durante o cultivo de P. sajor-caju. Já BANIK e NANDI (2004) descrevem o aumento da eficiência biológica de $P$. sajor-caju cultivado em palha de arroz suplementada com esterco na proporção de 1:1. Por outro lado, Moda et al. (2005) citam que para o cultivo deste mesmo cogumelo em bagaço de cana-de-açúcar suplementado com quirela de milho diminui a eficiência biológica.

Conforme a tabela 3 , verifica-se que a linhagem PSC96/03 possui maior teor de proteína diante das outras linhagens, tendo a BF24 maior teor de lipídios seguida de PSC01/06 e PSC96/03 respectivamente. Quanto aos teores de carboidratos e cinzas, nas diferentes espécies e linhagens não há diferenças significativas. Para a quantidade de fibras, nas linhagens BF24 e PSC01/06 não houve diferenças entre si, porém foram superiores a PSC96/03.

Dentre as três linhagens de Pleurotus sp. analisadas aquela com maior teor de proteína também proporcionou menores teores de lipídios. Cultivando P. sajor-caju em palha de arroz, BANIK e NANDI (2004) obtiveram valores de proteínas $(21,56 \%)$ e cinzas $(7,49 \%)$ abaixo dos constantes neste trabalho, mas os mesmos autores descrevem valores superiores para carboidratos $(28,81 \%)$ e lipídios $(10,43 \%)$. BONATTI et al. (2004) citam $42,8 \%$ de carboidratos, 5,59\% de cinzas, $9,60 \%$ de fibras e $13,0 \%$ de proteínas para a linhagem CCB019 de P. sajor-caju quando cultivada em palha de arroz, sugerindo que as variações nos valores nutricionais, entre as linhagens e espécies de cogumelos utilizadas, podem ser atribuídas às suas diferenças genéticas e nutricionais. Este fato foi descrito por MENDEZ et al. (2005), que mencionam que estas diferenças podem ser atribuídas pela variabilidade genética do fungo. Por outro lado SHASHIREKHA et al. (2005) associam estas variações aos tipos de substratos utilizados durante o cultivo.

Tabela 3. Composição físico-química de três linhagens de Pleurotus, produzidos durante dois fluxos de produção em substrato a base de capim-elefante, expressos em porcentagem em base seca

\begin{tabular}{lccc}
\hline & \multicolumn{3}{c}{ Cogumelos } \\
\cline { 2 - 4 } Determinações & Pleurotus ostreatus & Pleurotus sajor-caju & Pleurotus sajor-caju \\
& $22,59 \pm 1,764 \mathrm{~b}$ & PSC96/03 & PSC01/06 \\
\hline Proteínas (\%) & $0,88 \pm 0,024 \mathrm{a}$ & $29,24 \pm 0,822 \mathrm{a}$ & $25,51 \pm 0,854 \mathrm{~b}$ \\
Lipídios (\%) & $25,69 \pm 1,060 \mathrm{a}$ & $0,30 \pm 0,023 \mathrm{c}$ & $0,54 \pm 0,023 \mathrm{~b}$ \\
Carboidratos (\%) & $18,25 \pm 0,906 \mathrm{a}$ & $28,73 \pm 1,949 \mathrm{a}$ & $27,66 \pm 2,976 \mathrm{a}$ \\
Fibras (\%) & $32,58 \pm 0,867 \mathrm{a}$ & $10,32 \pm 1,484 \mathrm{~b}$ & $15,431,953 \mathrm{a}$ \\
Cinzas (\%) & $31,411,339 \mathrm{a}$ & $30,85 \pm 2,407 \mathrm{a}$ \\
\hline
\end{tabular}

Médias seguidas de mesma letra minúscula, nas linhas, não diferem entre si pelo teste de Duncan ( $\alpha=0,05)$.

Os valores correspondem à média aritmética de três repetições \pm desvio-padrão. 
Logo, visto ao exposto, verifica-se a possibilidade de cultivo de Pleurotus em substrato capim-elefante pasteurizado, obtendo alimento de altos valores nutricionais, podendo também ser desenvolvido como uma atividade complementar de renda.

\section{CONCLUSÕES}

1. Pleurotus ostreatus (BF24) possui maiores valores para massa fresca, eficiência biológica e produtividade, em relação ao Pleurotus sajor-caju (PSC96/03 e PSC01/06) cultivados em substrato capim-elefante.

2. A linhagem PSC96/03 de Pleurotus sajor-caju possui maior teor de proteína e os menores teores de lipídios e fibras.

3. Em dois fluxos de produção para três linhagens de Pleurotus, $90 \%$ da produção ocorre no primeiro fluxo, em torno de 40 dias de cultivo.

4. O cultivo de Pleurotus ostreatus e P. sajor-caju pode ser realizado em substrato apenas pasteurizado a $100^{\circ} \mathrm{C} / 30$ minutos, eliminando-se o processo de compostagem.

\section{REFERENNCIAS}

BANIK, S.; NANDI, R. Effect of supplementation of rice straw with biogas residual slurry manure on the yield, protein and mineral contents of oyster mushroom. Industrial Crops and Products, v.20, p.311-319, 2004.

BERNARDI, E. Cultivo de Pleurotus spp. em substrato capimelefante (Pennisetum purpureum Schum) pasteurizado. 2007. 81f. Dissertação (Mestrado em Produção Vegetal) Universidade Federal de Pelotas, Pelotas.

BONATTI, M.; KARNOPP, P.; SOARES, H.M., FURLAN, S.A. Evaluation of Pleurotus ostreatus and Pleurotus sajor-caju nutritional characteristics when cultivated in different lignocellulosic wastes. Food Chemistry, v.88, p.425-428, 2004.

CURVETTO, N.R.; FIGLAS, D.; DEVALIS, R.; DELMASTRO, S. Growth and productivity of different Pleurotus ostreatus strains on sunflower seed hulls supplemented with $\mathrm{N}-\mathrm{NH}_{4}{ }^{+}$and/or Mn(II). Bioresource Technology, v.84, p.171-176, 2002.

DIAS, E.S.; KOSHIKUMO, E.M.S.; SCHWAN, R.F; SILVA, R. Cultivo do cogumelo Pleurotus sajor-caju em diferentes resíduos agrícolas. Ciência e Agrotecnologia, v.27, p.13631369, 2003.

DONINI, L.P.; BERNARDI, E.; MINOTTO, E.; NASCIMENTO, J.S. Desenvolvimento in vitro de Pleurotus sp. sob a influência de diferentes substratos e dextrose. Arquivos do Instituto Biológico, v.72, p.331-338, 2005.
EIRA, A.F. Cultivo do "cogumelo-do-sol" (Agaricus blazei (Murrill) ss. Heinemann. Viçosa: Aprenda Fácil, 2003. 203p.

EIRA, A.F.; MINHONI, M.T.A. Manual teórico-prático do cultivo de cogumelos comestíveis. 2.ed. Botucatu: Fundação de Estudos e Pesquisas Agrícolas e Florestais, 1997. 115p.

HOSSAIN, S.; HASHIMOTO, M.; CHOUDHURY, E.; ALAM, N.; HUSSAIN, S.; HASAN, M.; CHOUDHURY, S.; MAHMUD, I. Dietary mushroom (Pleurotus ostreatus) ameliorates atherogenic lipid in hypercholesterolaemic rats. Clinical and Experimental Pharmacology and Physiology, v.30, p.470-475, 2003.

INSTITUTO ADOLFO LUTZ. Normas analíticas: Métodos químicos e físicos para análise de alimentos. 3. ed. São Paulo, 1985. 533p.

KALMIS, E.; SARGIN, S. Cultivation of two Pleurotus species on wheat straw substrates containing olive mill waste water. International Biodeterioration \& Biodegradation v.53, p.4347, 2004.

KIM, S.; KIM, H.; LEE, B.; HWANG, H.; BAEK, D.; KO, S. Effects of mushroom, Pleurotus eryngii, extracts on bone metabolism. Clinical Nutrition, v.25, p.166-170, 2006.

KOPYTOWSKI FILHO, J. Relação C/N e proporção de fontes nitrogenadas na produtividade de Agaricus blazei Murril e poder calorífico do composto. 2002. $101 \mathrm{f}$. Dissertação (Mestrado em Agronomia) - Faculdade de Ciências Agronômicas, Universidade Estadual Paulista, Botucatu.

LI, X.; PANG, Y.; ZHANG, R. Compositional changes of cottonsed hull substrate during $P$. ostreatus growth and the effects on the feeding value of the spent substrate. Bioresource Technology, v.80, p. 157-161, 2001.

MANDEEL, Q.A.; AL-LAITH, A.A.; MOHAMED, S.A. Cultivation of oyster mushrooms (Pleurotus spp.) on various lignocellulosic wastes. World Journal of Microbiology \& Biotechnology, v.21, p.601-607, 2005.

MENDEZ, L.A.; CASTRO, C.A.S.; CASSO, R.B.; LEAL, C.M.C. Effect of substrate and harvest on the amino acid profile of Oyster mushroom (Pleurotus ostreatus). Journal of Food Composition and Analysis, v.18, p.447-450, 2005.

MODA, E.M.; HORII, J.; SPOTO, M.H.F. Edible mushroom Pleurotus sajor-caju production on washed and supplemented sugarcane bagasse. Scientia Agricola, v.62, p.127-132, 2005.

RAGUNATHAN, R.; SWAMINATHAN, K. Nutritional status of Pleurotus spp. grown on various agro-wastes. Food Chemistry, v.80, p.371-375, 2003.

ROYSE, D.J. Influence of spawn rate and commercial delayed release nutrient levels on Pleurotus cornucopiae (oyster mushroom) yield, size, and time to production. Applied Microbiology and Biotechnology, v.58, p.527531, 2002. 
SHASHIREKHA, M.N.; RAJARATHNAM, S.; BANO, Z. Effects of supplementing rice straw growth substrate with cotton seeds on the analytical characteristics of the mushroom, Pleurotus florida (Block \& Tsao). Food Chemistry, v.92, p.255259, 2005.

SILVA, S.O.; COSTA, S.M.G.; CLEMENTE, E. Chemical composition of Pleurotus pulmonarius (Fr.) Quél., substrates and residue after cultivation. Brazilian Archives of Biology and Technology, v.45, p.531-535, 2002.

STURION, G.L. Utilização da folha de bananeira como substrato para o cultivo de cogumelos comestíveis (Pleurotus spp.). 1994. 56f. Dissertação (Mestrado em Ciência e Tecnologia de Alimentos) - Escola Superior de Agricultura Luiz de Queiroz, Piracicaba.

TEDESCO, M.J.; GIANELLO, C.; BISSANI, C.A.; BOHNEN, H.; VOLKWEISS, S.J. Análises de solo, plantas e outros materiais. 2.ed. Porto Alegre: UFRGS/Departamento de Solos, 1995. 443p. (Boletim Técnico, 5)

TISDALE, T.E.; MIYASAKA, S.C.; HEMMES, D.E. Cultivation of the oyster mushroom (Pleurotus ostreatus) on wood substrates in Hawaii. World Journal of Microbiology \& Biotechnology, v.22, p.201-206, 2006.

VELÁZQUEZ-CEDEÑO, M.A.; MATA, G.; SAVOIE, J. Wastereducing cultivation of Pleurotus ostreatus and Pleurotus pulmonarius on coffee pulp: changes in the production of some lignocellulolytic enzymes. World Journal of Microbiology \& Biotechnology, v.18, p.201-207, 2002.

VOGEL, F.; SALMONES, D. Análisis comparativo de la productividad de cepas de Pleurotus spp. cultivadas em uma planta comercial. Revista Iberoamericana de Micologia, v.17, p.138-141, 2000.

WANG, D.; SAKODA, A.; SUZUKI, M. Biological efficiency and nutritional value of Pleurotus ostreatus cultivated on spent beer grain. Bioresource Technology, v.78, p.293-300, 2001.

YILDIZ, S.; YILDIZ, Ü.C.; GEZER, E.D.; TEMIZ, A. Some lignocellulosic wastes used as raw material in cultivation of the Pleurotus ostreatus culture mushroom. Process Biochemistry, v.38, p.301-306, 2002.

YILMAZ, N.; SOLMAZ, M.; TÜRKEKUL, I.; ELMASTAS, M. Fatty acid composition in some wild edible mushrooms growing in the middle Black Sea region of Turkey. Food Chemistry, v.99, p.168-174, 2006.

ZANETTI, A.L.; RANAL, M.A. Suplementação da cana-deaçúcar com guandu no cultivo de Pleurotus sp. 'Florida'. Pesquisa Agropecuária Brasileira, v.32, p.959-964, 1997.

ZHANG, R.; LI, X.; FADEL, J.G. Oyster mushroom cultivation with rice and wheat straw. Bioresource Technology, v.82, p.277-284, 2002.

ZONTA, E.P.; MACHADO, A.A. SANEST - Sistema de Análise Estatística para Microcomputadores. Registrado na Secretaria Especial de Informática sob n 066060 - categoria A. Pelotas, RS: Universidade Federal de Pelotas, 1984. 